\title{
Polyhydroxyalkanoate (PHA): Review of synthesis, characteristics, processing and potential applications in packaging
}

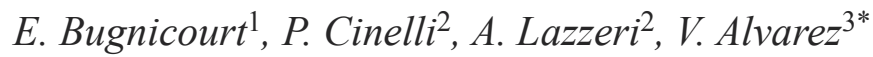 \\ ${ }^{1}$ Innovació i Recerca Industrial i Sostenible (IRIS), Parc Mediterrani de la Tecnologia Avda. Carl Friedrich Gauss No. 11, \\ 08860 Castelldefels (Barcelona), Spain \\ ${ }^{2}$ UdR Consortium INSTM - Department of Civil and Industrial Engineering, University of Pisa, Largo Lucio Lazzarino 1, \\ 56126 Pisa, Italy \\ ${ }^{3}$ INTEMA, Composite Materials Group (CoMP), Engineering Faculty, National University of Mar del Plata, Juan B. Justo \\ 4302 (B7608FDQ) Mar del Plata, Argentina
}

\begin{abstract}
Polyhydroxyalkanoates (PHAs) are gaining increasing attention in the biodegradable polymer market due to their promising properties such as high biodegradability in different environments, not just in composting plants, and processing versatility. Indeed among biopolymers, these biogenic polyesters represent a potential sustainable replacement for fossil fuel-based thermoplastics. Most commercially available PHAs are obtained with pure microbial cultures grown on renewable feedstocks (i.e. glucose) under sterile conditions but recent research studies focus on the use of wastes as growth media. PHA can be extracted from the bacteria cell and then formulated and processed by extrusion for production of rigid and flexible plastic suitable not just for the most assessed medical applications but also considered for applications including packaging, moulded goods, paper coatings, non-woven fabrics, adhesives, films and performance additives. The present paper reviews the different classes of PHAs, their main properties, processing aspects, commercially available ones, as well as limitations and related improvements being researched, with specific focus on potential applications of PHAs in packaging.
\end{abstract}

Keywords: biodegradable polymers, biopolymers, polyhydroxyalkanoates (PHAs), polyhydroxybutyrate

\section{Introduction}

Biopolymers or organic plastics are a form of plastics derived from renewable biomass sources such as vegetable oil, starch, proteins etc, unlike fossilfuel plastics which are derived from petroleum. Biopolymers provide the dual advantages of conservation of fossil resources and reduction in $\mathrm{CO}_{2}$ emissions, which make them an important innovation of sustainable development.

In recent years more and more biopolymers have been studied by researchers revealing a large range of possible sources from which they can be obtained and an increasing range of applications that bio plastic produced from them can fulfil. The possible sources range from different types biomass (Figure 1) including proteins (from animal and vegetal sources which are gaining interest due to their high functionality and excellent properties) [1] lipids and polysaccharides (e.g. starch and cellulose based biopolymers).

Others include bio-based polymers obtained from bio-derived monomers, e.g. from corn, which are then polymerized through standard routes. This is the case for biopolyesters such as polylactic acid

\footnotetext{
${ }^{*}$ Corresponding author, e-mail: alvarezvera@gmail.com

(C) BME-PT
} 


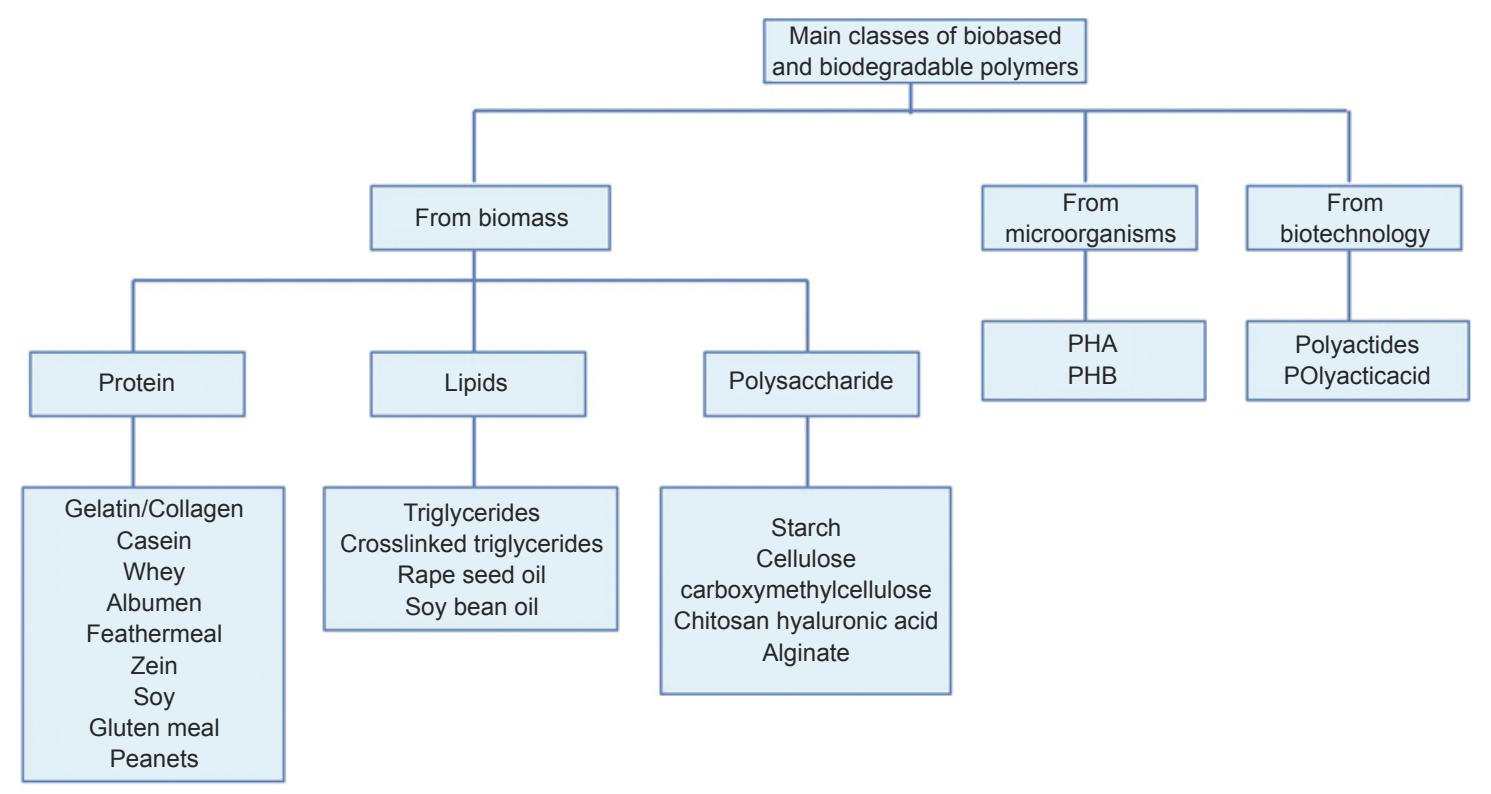

Figure 1. Different classes of polymers which are biobased and biodegradable (therefore not including biodegradable plastics from petrochemical resources and non biodegradable partly or fully biosourced plastics)

(PLA), until recently the most widely available biopolymer on the market, and set to be out ranked by bio-based polyethylene therephtalate (PET) or polyethylene (PE), among others, also obtained via a similar synthesis route. In contrast, polyhydroxyalkanoates (PHAs) are biogenic polyesters that can be naturally accumulated in microbial cultures. Among this latter category, obtained via so called bio-refineries, algae serve as an excellent pathway for plastic production owing to their numerous advantages such as high yield and the ability to grow in a range of environments. Algae biopolymers mainly evolved as a by-product of algae biofuel production, where companies were exploring alternative sources of revenue in addition to those obtained from the biofuels. Moreover the use of algae opens up the possibility of utilizing carbon, neutralizing greenhouse gas emissions from factories or power plants. Algae based plastics have been a recent trend in the era of bioplastics compared to traditional methods of utilizing feedstock, such as starch from corn and potatoes, in polymers production, and plastic formulations.

Various processes for the cultivation of algae and production of biopolymers exist. Fundamentally, they comprise two stages: a first stage, in which algae growth is initiated and a second stage where the biopolymer accumulation is promoted. Although increasing research on the use of microalgae for such production, e.g. PHA, most studies are still at the academic level and have not yet penetrated the industry [2].

While polymers synthesized by (micro) algae are in their infancy, once they are moved into commercialization they are likely to find applications in a wide range of industries. Other possible routes for the use of algae derived monomers for subsequently synthesizing PLA are also being investigated and composites including algae derived natural fibres in their formulations are now commercially available. Bioplastics are generating increasing interest, for industries and their market is rising as a result of technological advances and cost reductions. The advantages of bioplastics over traditional plastics are unprecedented, provided that they are used in situations in which they enable improved functionality and generate extra benefits. Biopolymers, from which bioplastics are produced, are generally more sustainable materials than their petrochemical-based counterparts, and, as previously mentioned, they can be produced from a wide range of renewable resources including more and more wastes and nonfood competing sources as opposed to early biopolymers which diverted full corn fields for the production of starch as raw material for polymers production, that coupled with the production of ethanol. The practical side of the use of biopolymers is related to the economic advantage for industries and municipalities. These consist of the saving of raw materials and the reduction in costs when the products are 
finally discarded. Renewable biologically degradable products also contribute to a sustainable economy. This means that the agricultural sector obtains the possibility to get a rising percentage of its additional turnover from non-food products. After the disposal of the products, the recovered materials can be taken back by the agriculture as certificate quality-compost with economical (and ecological) advantages.

Packaging is the biggest polymer processing industry with the food sector being its principal customer. Despite environmental problems, the European polymer packaging market is increasing in the order of millions of tons per year. In the wake of future laws in relation to reducing the weight and volume of these products, cheap and biodegradable polymeric products are receiving growing attention in this market [3]. The materials used for this application often have short service time, so they end up mostly in landfills and stay there for over 100 years ([4-8]). When products, such as bags and bottles, are discarded, it is not possible in several cases, to collect them, and can end up clogging sewers and drains, and polluting streets, beaches and scenery, having a very costly impact on waste management. Plastic pollution is creating significant environmental and economic burdens since plastics deplete natural fuels (energy) and other natural resources [9]. The use of biodegradable plastics can serve as a response to this issue. This idoneous solution is well reflected by the volume of bioplastics altogether going to packaging and bottle applications nowadays, which is far greater than the average for standard plastics.

Efforts allowing the development of tailored solutions for this sector are therefore extremely relevant. Other applications include household/consumer/ catering products, medical disposable devices, etc. In such a context, although they still occupy a very limited market share, PHAs are gaining attention among biodegradable polymers due to their promising properties such as high biodegradability in different environments, not just in composting plants, and versatility. Indeed, PHAs can be then formulated and processed for use in many applications, including packaging, moulded goods, paper coatings, nonwoven fabrics, adhesives, films and performance additives. As opposed to other biopolymers, for example due to their good thermomechanical and barrier properties, PHAs offer great potential for packaging applications. Their properties, capacities for deriving a range of compounds with variable behaviour, processability, as well as the state of academic developments and current shortcomings, commercially available products and applications are reviewed hereafter.

\section{Polyhydroxyalkanoate polymers}

Due to their previously discussed benefits, interest in biodegradable polymers produced from renewable resources has increased significantly in recent years. Polyhydroxyalkanoate polymers are naturally produced by bacteria in general cultivated on agricultural raw materials. They can be processed to make a variety of useful products, where their biodegradability and naturalness are quite beneficial in particular for application in single use packaging and agriculture.

Poly(3-hydroxybutyrate) (PHB), Figure 2a, is a homopolymer of 3-hydroxybutyrate and is the most widespread and best characterized member of the polyhydroxy-alkanoate family. Other members of family are displayed in Figures $2 b$ and $2 c$.

Poly-3-hydroxybutyrate (PHB) is a linear polyester of D (-)-3-hydroxybutyric acid which was first discovered in bacteria by Lemoigne in 1925. It is accumulated in intracellular granules by a wide variety of Gram-positive and Gram-negative organisms under conditions of a nutrient limitation other than the carbon source [10]. The molecular weight of PHB differs depending on the organism, conditions of growth and method of extraction, and can vary from about 50000 to well over a million. The polymer possesses the important properties of thermoplasticity and biodegradability in compost and different environments comprising marine water, and, in consequence, has attracted considerable commercial interest.

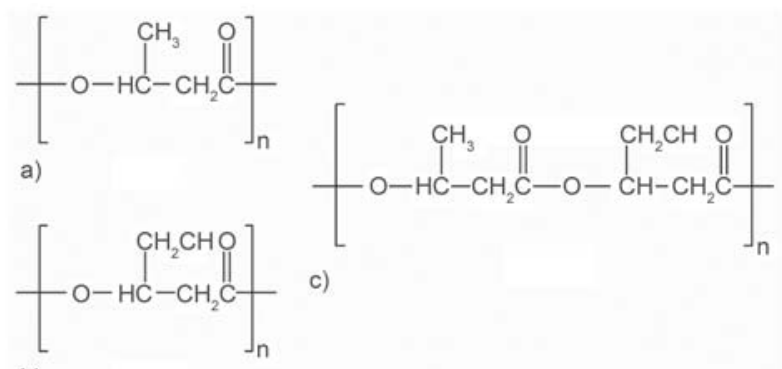

b)

Figure 2. Chemical structure of some polyhydroxyalkanoates, a) PH3B, b) PHV, c) PHBV 
PHB is apparently produced by microorganisms (such as Ralstonia eutrophus or Bacillus megaterium) in response to conditions of physiological stress and can be produced either by pure culture than mixed culture of bacteria [11]. The polymer is primarily a product of carbon assimilation (from glucose or starch) and is employed by microorganisms as a form of energy storage molecule to be metabolized when other common energy sources are not available. Microbial biosynthesis of PHB starts with the condensation of two molecules of acetyl-CoA to give acetoacetyl-CoA, which is subsequently reduced to hydroxybutyryl-CoA. This latter compound is then used as a monomer to polymerize PHB.

Biologically produced, polyhydroxybutyrate (PHB) is a semicrystalline isotactic stereo regular polymer with $100 \% \mathrm{R}$ configuration that allows a high level of degradability [12]. PHB is presented here as an example of how new technology, derived from nature but not exploited until recently, can contribute to meeting societal needs for plastics and a clean environment.

\subsection{General properties of polyhydroxyalkanoates}

PHAs polymers are thermoplastic and they differ in their properties depending on their chemical composition (homo-or copolyester, contained hydroxy fatty acids). Some grades of additivated PHB are similar in their material properties to polypropylene (PP), and offer good resistance to moisture and aroma barrier properties. Polyhydroxybutyric acid synthesized from pure PHB is relatively brittle (i.e. elongation at break typically below $15 \%$ ) and stiff (i.e. $E$ modulus above $1 \mathrm{GPa}$ ). For example, mechanical properties of specimen prepared with PHB Biomer LoT13 without any additive were reported (original data from the authors). PHB is a fragile material due to re-crystallization with ageing at room temperature as will be extensively reported in following sections. Thus mechanical properties change with time and, as reported in the example, samples stored at room temperature for 60 days have lower values for elongation at break than samples stored for 30 days. For these reasons, efforts in compounding PHB are mainly focused on the search of plasticizers and nucleating agents capable of reducing the crystallization process and improving flexibility

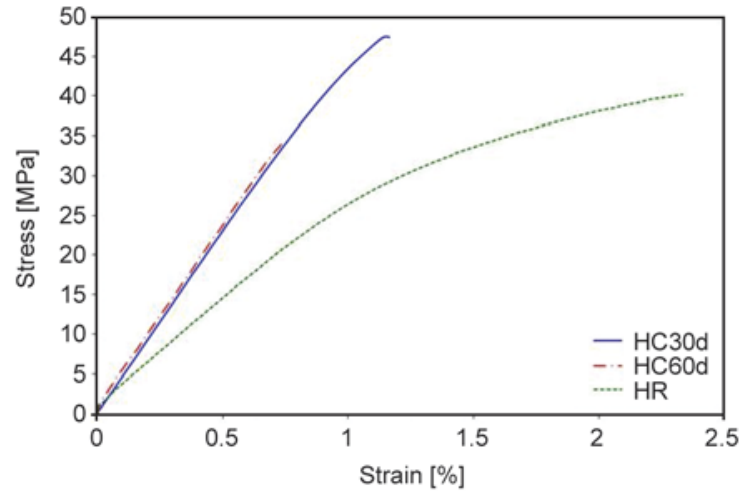

Figure 3. Stress/strain of PHB $(\mathrm{H})$ samples stored at 50\% $\mathrm{RH}$ for respectively 30 (HC30d) and 60 days (HC60d), and stored at low temperature (HR) $\left(5^{\circ} \mathrm{C}\right)$

and elongation in the final product. Figure 3 shows the stress/strain of PHB (H) samples stored at 50\% $\mathrm{RH}$ for respectively 30 (HC30d) and 60 days (HC60d), and stored at low temperature (HR) $\left(5^{\circ} \mathrm{C}\right)$. Some of the general characteristics of PHAs are summarized in the following paragraphs:

- Water insoluble and relatively resistant to hydrolytic degradation.

- Good ultra-violet resistance but poor resistance to acids and bases.

- Soluble in chloroform and other chlorinated hydrocarbons.

- Biocompatible and hence suitable for medical applications.

- Sinks in water, facilitating its anaerobic biodegradation in sediments.

- Nontoxic.

- Less 'sticky' than traditional polymers when melted.

The average properties of PHA's are summarised in Table 1.

Table 1. Range of typical properties of PHA's

\begin{tabular}{|l|c|}
\hline \multicolumn{1}{|c|}{ Property $^{*}$ [units] } & Values \\
\hline$T_{\mathrm{g}}\left[{ }^{\circ} \mathrm{C}\right]$ & 2 \\
\hline$T_{\mathrm{m}}\left[{ }^{\circ} \mathrm{C}\right]$ & $160-175$ \\
\hline$X_{\mathrm{cr}}[\%]$ & $40-60$ \\
\hline $\mathrm{E}[\mathrm{GPa}]$ & $1-2$ \\
\hline$\sigma[\mathrm{MPa}]$ & $15-40$ \\
\hline$\varepsilon[\%]$ & $1-15$ \\
\hline $\mathrm{WVTR}\left[\mathrm{g} \cdot \mathrm{mm} / \mathrm{m}^{2} \cdot\right.$ day $]$ & 2.36 \\
\hline OTR $\left[\mathrm{cc} \cdot \mathrm{mm} / \mathrm{m}^{2} \cdot\right.$ day $]$ & 55.12 \\
\hline
\end{tabular}

${ }^{*} T_{\mathrm{g}}$ : glass transition temperature, $T_{\mathrm{m}}$ : melting temperature,

$X_{\text {cr: }}$ crystallinity degree, $E$ : Young's modulus, $\sigma$ : tensile strength, $\varepsilon$ : elongation at break, WVTR: water vapour transmission rate;

OTR: oxygen transmission rate. 


\subsection{Thermal and mechanical properties of polyhydroxyalkanoates}

Isostatic PHB displays a number of properties comparable to petroleum-based polymers (e.g., polypropylene), such as high melting temperature $\left(175^{\circ} \mathrm{C}\right)$ and relatively high tensile strength (30-35 MPa). However, pure PHB has had only limited use mainly because of its intrinsic brittleness (presenting low strain at break) and the narrow processing window of this plastic. Indeed, the elongation at break is very different between PHB (5\%) and PP (400\%). PHB/V (polyhydroxybutyrate/valerate) is also brittle, its elongation at break is less than $15 \%$, its modulus and fracture stress are $1.2 \mathrm{GPa}$ and $25 \mathrm{MPa}$ [13]. There are many reasons for the brittleness of PHB and PHB/V: the secondary crystallization of the amorphous phase takes place during storage at room temperature; the glass transition temperature $\left(T_{\mathrm{g}}\right)$ of PHB is close to room temperature; PHB has a low nucleation density, therefore large spherulites exhibit inter-spherulitic cracks. Several authors ([14, 15]) have examined secondary crystallization, which occurs during storage time at room temperature. Due to its natural origin, PHB is free of heterogeneities, like catalyst residues or other impurities that can act as heterogeneous nuclei, promoting the onset of crystallization [16]. This affects the crystallization kinetics of the polymer, which often starts from homogeneous nuclei, unless specific nucleating agents are added. The slow crystallization kinetics of PHB permits to tune the crystallinity level, which, in turn, is expected to affect also the rigid amorphous chains coupled with the crystals. By the addition of a nucleating agent, the number of small spherulites increases. It is reported that the rigid amorphous fraction of low-molarmass PHB of $5 \mathrm{kDa}$ is only $5-10 \%$, and at best half of that of high-molar-mass PHB of almost $500 \mathrm{kDa}$, despite identical crystallinity. The larger rigid amorphous fraction and higher degree of reversible melting and crystallization in PHB of high molar mass, consistently and independently, is attributed to enhanced covalent coupling of crystals and amorphous structure, and/or de-coupling of segments of macromolecules which traverse between phases, respectively [17]. Molecule segments in the amorphous phase exhibit a reduced mobility if they are covalently connected with the crystalline phase.

This part of the amorphous phase is commonly named rigid amorphous fraction (RAF) that was reported to be around $20-30 \%$ of the overall sample mass ([17-19]), The kinetics of vitrification of the RAF of PHB was quantified upon quasi-isothermal cold crystallization at $22.8^{\circ} \mathrm{C}$, and it was found that the whole RAF of PHB is established during crystallization [20] In a recent study, it was proven that the physical state of the amorphous layer in contact with the growing crystals influences the mechanism of crystallization of PHB. During heating of an initially amorphous PHB, the rigid amorphous fraction, which is established simultaneously with formation of the crystals during the first stage of cold crystallization, slows down further crystal growth, which can proceed only upon further increase of the temperature, when complete mobilization of the RAF is achieved [19].

On addition of plasticizers, the molecular motion is enhanced, and the glass transition is lowered. To achieve high elongation at break and a higher flexibility for modified/formulated PHB, the glass transition temperature must reach lower value than the testing temperature. The elongation and impact strength depend on the $T_{\mathrm{g}}$ as well as the morphology. In the blends, the nucleation rate and spherulite size depend on the cooling rate and nucleation density, i.e., fast cooling after melting increases the crystallization rate. That forms fine spherulites and suppresses crystallinity. This is required for the achievement of the necessary mechanical properties.

Moreover, PHB thermally decomposes at temperatures just above its melting point. A short exposure of PHB to temperature near $180^{\circ} \mathrm{C}$ could induce a severe degradation accompanied by production of the degraded products of olefinic and carboxylic acid compounds, e.g., crotonic acid and various oligomers: through the random chain scission reaction that involves a cis-elimination reaction of $b-$ $\mathrm{CH}$ and a six-member ring transition ([21-23]).

The very low resistance to thermal degradation seems to be the most serious problem related to the processing of PHB. The main reaction involves chain scission, which results in a rapid decrease in molecular weight [24]. The most common mechanisms are summarised in Figure 4.

During processing, the degradation of the chains may be reduced by the addition of a lubricant that prevents the degradation of the chains in processing, so that the material can be processed at 170$180^{\circ} \mathrm{C}$, because PHB is sensitive to high processing temperatures. This leads to a decrease in the molec- 


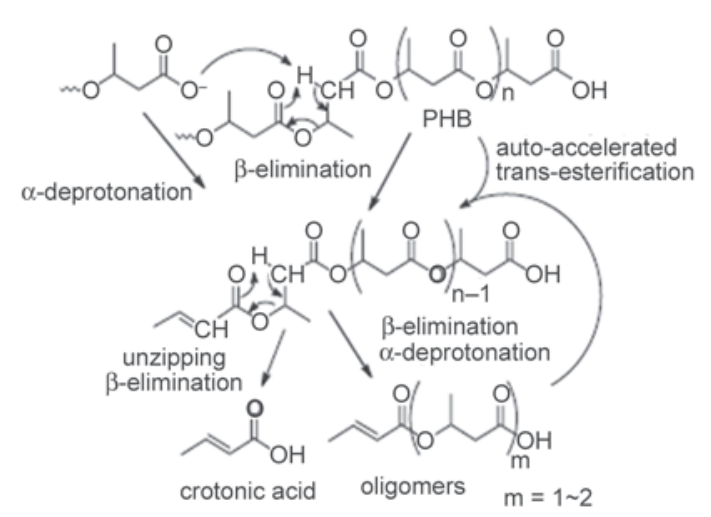

Figure 4. Mechanism of thermal degradation for PHB

ular weight, as well as a reduction in the melt viscosity. The crystallization temperature shifts to lower values, and crystallization takes longer.

In the study of thermal properties of PHB by differential scanning calorimetry (DSC) a double melting peak is reported in the literature [25] and attributed to a bimodal distribution of crystallite size resulting from changes in molecular weight due to random scission of long PHB chains that takes place at high temperatures, i.e. to the decrease in the molecular weight. PHB is also known to present irregularly shaped exotherm peaks during crystallization [26]. When the number of growing spherulites is low, the evolution of latent heat is very sensitive to every act of nucleation as well as to the space limitations in the process of growth, resulting in non-monotonous development of latent heat, with sudden increases and decreases in crystallization rates. This results in non-conventional DSC exotherms, under given crystallization conditions, characterized by spikes or shoulders associated to nucleation of new spherulites. In dynamic mechanical thermal analysis (DMTA) curves, PHB has two processes, the main one associated with glass transition reflects the motions in connection with the chains in the amorphous regions while the peak at higher temperature reflects the chain mobility between the crystalline melting and amorphous process; it depends on the thickness of the lamellae [27]. Other authors also reported that PHB possesses relaxations at $20^{\circ} \mathrm{C}$ and $100-150^{\circ} \mathrm{C}$ $([28,29])$.

One of the main approaches to improve the properties of PHB is the production of derivatives based on PHB via the biosynthesis of copolyesters containing PHB units with other 3-hydroxyalkanoates units [30], such as poly (3-hydroxybutyrate-cohydroxyvalerate) (PHBV) [31] or poly (3-hydroxy- butyrate-co-3-hydroxyhexanoate) [32], with different molar ratios of hydroxycarboxylic acids. This approach has been investigated extensively [33] because it can effectively improve mechanical properties [34] and lower the melting point, avoiding degradation during processing. However, blends with other biodegradable polymers and composites based on PHB that exclude any synthetic component are also very convenient as industrial materials due to their easier processability and lower cost $([35,36])$.

As reported above, the addition of plasticizers is considered as a relatively simple route to modify the thermal and mechanical properties of polymers. Blending polymers with plasticizers may modify the physical properties of polymers and a decrease in processing temperature can be achieved. Thus PHB is commonly blended with plasticizers and nucleation agents that lead to a lower glass temperature and lower crystallinity due to the formation of numerous, small and imperfect crystallites.

\subsection{Blending of PHB with other polymers or plasticizers}

Blending PHAs and in particular PHB with other polymers, or with plasticizers, may offer opportunities to improve processability by lowering the processing temperature and reducing the brittleness of PHAs based plastics. So far many blends containing PHB/PHAs have been studied and also many types of plasticizers have been proposed ([37, 38]).

The literature reports the use as plasticizers from materials that are cheap and readily available on the market, and generally also of natural origin, such as oxypropylated glycerin (or laprol), glycerol, glycerol triacetate, 4-nonylphenol, 4,40-dihydroxydiphenylmethane, acetyl tributyl citrate, salicylic ester, acetylsalicylic acid ester, soybean oil, epoxidized soybean oil, dibutyl phthalate, triethyl citrate, dioctyl phthalate, dioctyl sebacate, acetyl tributyl citrate, di-2-ethylhexylphthalate, tri(ethylene glycol)-bis(2ethylhexanoate), triacetine, and fatty alcohols with or without glycerol fatty esters, polyethylene glycol (PEG) as well as low molecular weight polyhydroxybutyrate since PHAs with medium chain length are elastomers with low melting point and a relatively lower degree of crystallinity $([39,40])$.

Blends produced by solvent cast polyethylene glycol resulted well compatible with PHB [30] and miscibility was reported by study with DSC for low 
content of polyethylene glycol (2-5\%) in PHB [41]. The thermal properties of blends of PHB with PEG400 in different proportions $(2,5,10,40 \%)$ prepared by the casting of polymer solutions in chloroform was investigated (Parra 06). In these blends there was an increase in the elongation at break by up to about four times versus the original elongation at break of PHB and a reduction in the tensile strength. In this paper, DSC thermograms also show two melting peaks for PHB, lightly lowered by PEG addition. This behaviour was attributed to a plasticizing effect of PEG that weakened the intermolecular forces between the adjacent polymer chains. Consequently, there was a change in free volume that reduced the melting temperatures of the system. These authors classified PEG400 as a plasticizer for $\mathrm{PHB}$, due to a reduction in melting temperature of PHB in PHB/PEG blends.

Poly(3-hydrobutyrate) plasticized was prepared with dioctyl (o-)phthalate (DOP), dioctyl sebacate (DOS), and dioctyl sebacate (ATBC)(exploit) [42]. It was shown, from the DSC measurements, that only the addition of ATBC leads to an obvious decline in $T_{\mathrm{g}}$ and improves other thermal characteristics. However, it does little to improve the mechanical properties. They have also demonstrated that blending with $\mathrm{P}(3 / 4 \mathrm{HB})$ notably improves the mechanical properties of $\mathrm{PHB}$, with a good elongation at break reaching e.g. 10\%. The melt flow index (MFI) test has revealed that the addition of stabilizer antioxidant 1010 and the addition of Poly (3hydroxybutyrate-co-hydroxyhexanoate) PHBHHx and $\mathrm{P}(3 / 4 \mathrm{HB})$ both enhance the thermal stability of PHB and stabilize the MFI value. A combination of ATBC, antioxidant 1010, and PHBPHBHHx or poly (3-hydrobutyrate-co-4-hydrobutyrate) $\mathrm{P}(3 / 4 \mathrm{HB})$ could widen the PHB processing window.

Preliminary studies of PHB blended with PEG by extrusion outlined in this process as not having an efficient effect as a plasticizer of PEG in PHB ([2]). Tests have been reported with PHB, and polyethylene glycol PEG 400, and PEG 1500 prepared by extrusion and injection moulding for production of composites with wood fibres. It was observed that the PEG addition makes processing easier having a lubricant effect on melted PHB/wood formulations, but the PEG was not efficiently blended with PHB and with time leached to the surface and reduced its possible plasticizing effect. Moreover in these studies, the presence of PEG 1500 melting peak was observed in all the samples based on PHB with PEG 1500 suggesting that PEG 1500 is not completely compatible with PHB, as confirmed by separation observed in the samples with ageing.

In the preparation of nanocomposites of $\mathrm{PHB}$ with cellulose nanowhiskers (CNW) prepared through the previous dispersion of CNWs in polyethylene glycol (PEG) and subsequent incorporation of the $\mathrm{PEG} /$ nano whiskers dispersions into the biopolymer, it was observed that for CNW concentrations up to $0.45 \mathrm{wt} \%$, the CNWs were covered by PEG, and the interaction between the PHB and the CNWs occurred preferentially with PEG ([43]). The adhesion of PEG to the natural fibres can explain the lubricating effect of PEG in the preparation of composites with $\mathrm{PHB}$ and natural fibres.

Acetyl tributyl citrateate is also reported as a plasticizer for PHB. It is derived from naturally occurring citric acid and non-toxic [25]. Acetyl tributyl citrateate had a weak positive influence on thermal properties of PHB in the melt, but samples with PHB should be rapidly cooled down below the melting temperature in order to obtain the best processing conditions for the desired degree of crystallization. The use of glycerol, tributyrin, triacetin, acetyltriethylcitrate, acetyltributylcitrate as plasticizers, and saccharin have been reported as nucleation agents [13]. Lubricants were glycerolmonostearate, glyceroltristearate, 12-hydroxystearate and 12-hydroxystearic acid.

The copolymer, PHB-co-HV (poly-3-hydroxybutyrate-co-3-hydroxyvalerate), exhibits increased Temperature of crystallization $\left(T_{\mathrm{c}}\right)$ as compared to the homopolymer PHB. Increasing the molecular fraction of HV monomer in the PHB-co-HV initially led to a decrease in the melting temperature $\left(T_{\mathrm{m}}\right)$ of the copolymer from $175.4^{\circ} \mathrm{C}$ to a min. of $168.5^{\circ} \mathrm{C}$, at $20 \mathrm{~mol} \%$ of $\mathrm{HV}$, as it is shown in Figure 5 [44].

Subsequently, increases in the fractions of HV indicate a typical isodimorphic relationship. In a recent paper [45] two nucleating agents, heptane dicarboxylic derived HPN-68L and ULTRATALC 609, were tested to increase the $T_{\mathrm{c}}$ and reduce the time for crystallization necessary for injection moulding. HPN-68L decreased the Temperature of decomposition $\left(T_{\mathrm{dec}}\right)$ of the homopolymer and all copolymers by almost $50^{\circ} \mathrm{C}$. However, the use of ULTRATALC609 as a nucleating agent slightly enhanced the $T_{\mathrm{dec}}$ and had a negligible effect on the $T_{\mathrm{ms}}$ of all 


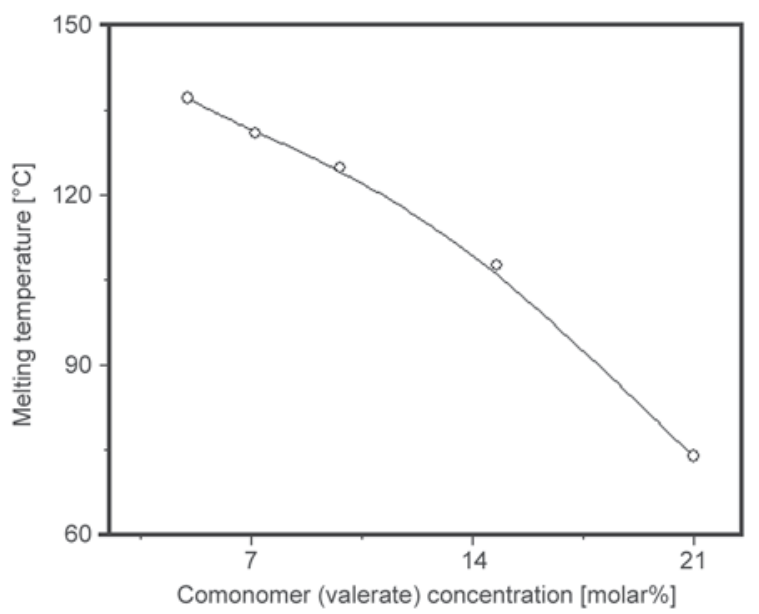

Figure 5. Effect of co monomer content $[\mathrm{mol} \%]$ on the melting temperature of PHB-V copolymers

polymers. Also, PHB and PHB-co-HV with $5 \mathrm{wt} \%$ of talc exhibited higher $T_{\mathrm{c}}$ than polymers without ULTRATALC609. A careful comparison of $T_{\mathrm{c}}, T_{\mathrm{m}}$ and $T_{\mathrm{dec}}$, for PHB-co-HV with $20 \mathrm{~mol} \%$ of $\mathrm{HV}$ indicated that this copolymer is the best option for injection moulding, with a high $T_{\mathrm{dec}}$.

Organo-modified montmorillonite (OMMT) clay as nanofiller has been used in blends with $\mathrm{PHB} / \mathrm{V}$ ) and acetyl tri-Bu citrate as a plasticizer [46]. These nano-biocomposites show an intercalated/exfoliated structure of the nanoadditive with good mechanical and barrier properties, and an appropriated biodegradation kinetic. The presence of the OMMT clay did not influence significantly the transition temperatures. However, the filler not only acted as a nucleating agent which enhanced the crystallization, but also as a thermal barrier, improving the thermal stability of the biopolymer. Vinyl acetate homopolymer or copolymer and optionally polyvinyl alcohol are also proposed for the toughening

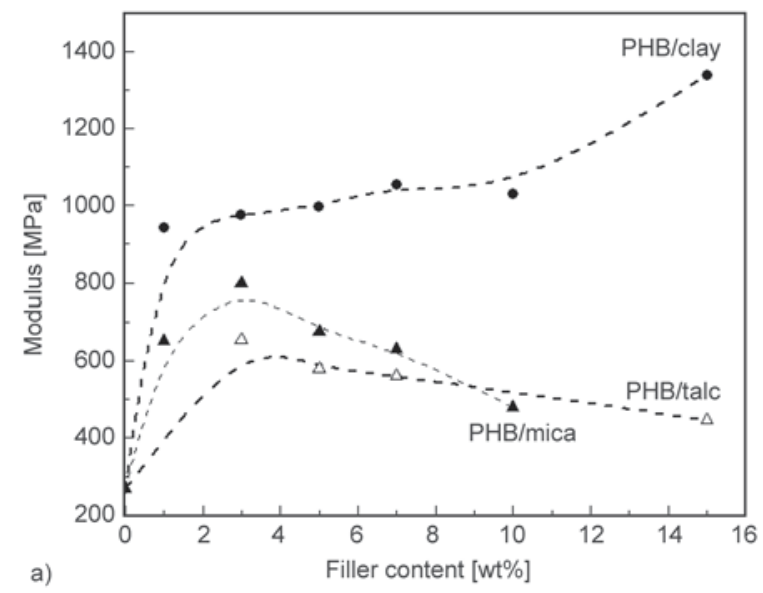

of PHAs blends [47]. Figures $6 a$ and $6 \mathrm{~b}$ show the effect of different filler content on the tensile properties (modulus and strength) of PHB [2, 48].

A good strategy to modify properties of PHB/PHAs in the solid-state is blending the polyester with a second polymeric component [49]. This route has been broadly explored, testing as the other blend component a vast range of thermoplastic polymers ([50-55]). Besides changing degree of crystallinity and width of the processing window, blending also offers the opportunity oflowerng production costs, that is at present the major problem for large-scale applications of bacterial polymers based plastics. $\mathrm{P}(3 \mathrm{HB})$ has been found to be miscible with various polymers, including poly(ethylene oxide) ([56]), poly(epichlorohydrin) ([57]) and poly(vinyl acetate) PVAc) [58], polyepsiol caprolactone ([54, 59]). Among polymers considered for blending with PHB there are also highly substituted cellulose esters and Tri-substituted cellulose butyrate ([60-63]).

The study of systems with immiscible binary blends with $\mathrm{P}(3 \mathrm{HB})$ are also important in controlling the profile of biodegradation [64]. $\mathrm{P}(3 \mathrm{HB}) /$ poly(propiolactone), $\mathrm{P}(3 \mathrm{HB}) /$ poly(ethylene adipate) and $\mathrm{P}(3 \mathrm{HB})$ /poly(3-hydroxybutyric acid-co-hydroxyvaleric acid) blends showed that they degrade faster than the pure components and the acceleration occurred due to the phase-separated structure [64].

Wood flour and lignin from different sources were used as fillers for the preparation of composite materials [65]. Natural fibres such as wood fibres act as load bearing constituents in the composite materials. Advantages of fibres derived from renewable resources on conventional reinforcements such as glass and aramid fibres are their relative cheapness, their ability to be recycled, and the fact that

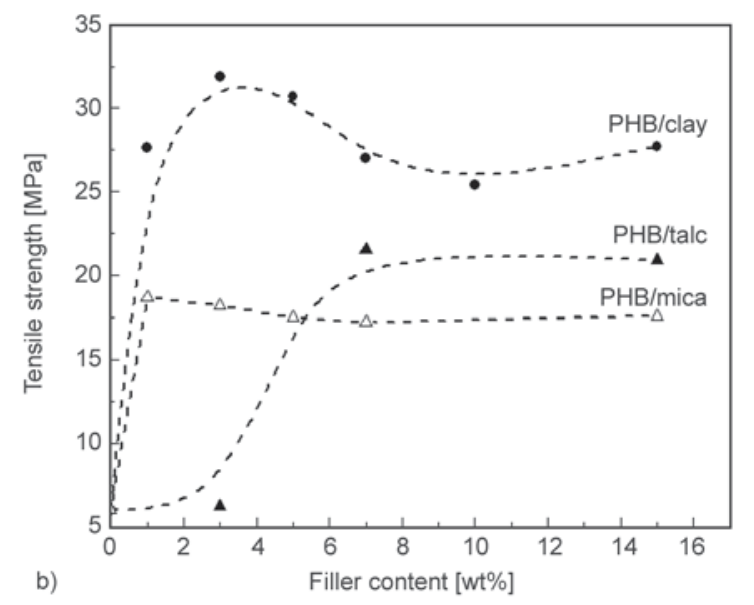

Figure 6. Effect of different filler contents on the tensile properties of PHB: a) modulus and b) strength 
they can compete well with them in terms of strength per weight of material [66].

\section{Processing considerations}

Depending on the molecular weight of the polymer but also on the comonomer content, different processing techniques can be used (Figure 7).

PHB as a powder can be blended with additives by mixing in a Brabender (kneader) at $170-180^{\circ} \mathrm{C}$ and $50 \mathrm{rpm}$ for 5 minutes or in a single screw extruder at a temperature in the range of $145^{\circ} \mathrm{C}$ (zone 1), $160^{\circ} \mathrm{C}$ (zone 2) and $170^{\circ} \mathrm{C}$ (zone 3 ) with $4 \mathrm{~mm}$ die and screw speed of $20 \mathrm{rpm}$. The strand (thread) is generally cooled in water and cut using a pelletizer. Then, the mixed material (granulates) can be compression moulded in a hydraulically heated press, commonly from $170-180^{\circ} \mathrm{C}$ between two sheets of Teflon for 2-5 minutes without pressure and an additional 1-3 minutes with pressure (50 bar). After moulding, the samples are cooled between cold metal plates with water. Plasticizers like glycerol, tributyrin, triacetin, acetyltriethylcitrate, acetyltributylcitrate are used in most cases. In addition, lubricants like glycerolmonostearate, glyceroltristearate, 12-hydroxystearat, and 12-hydroxystearicacid can also be used.

The different technologies that can be used for converting PHB are introduced below before an extensive discussion of the specificity of their use for processing PHB.

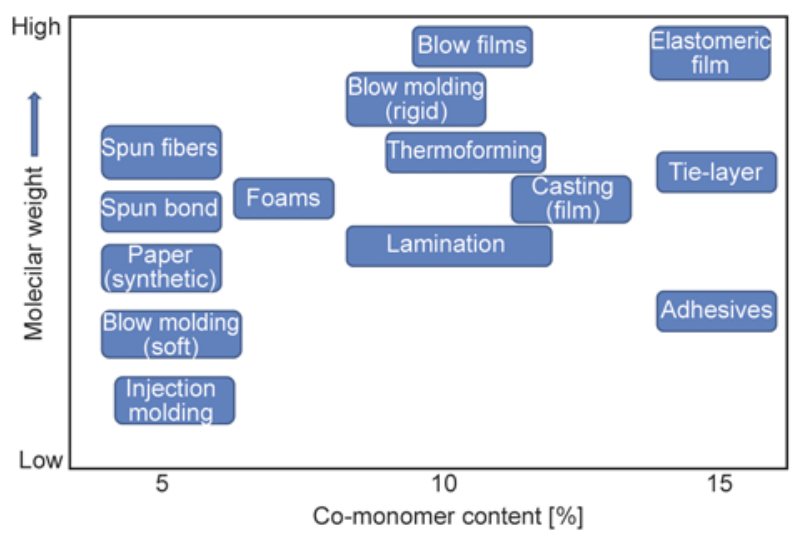

Figure 7. Adequate processing technique of different PHB copolymers, as a function of polymer molecular weight and co monomer content

\subsection{Melting behaviour of PHB}

PHB is a highly crystalline (60-70\% crystallinity) and linear polymer and the crystallization speed is fast between 80 and $100^{\circ} \mathrm{C}$ but slow below $60^{\circ} \mathrm{C}$ or above $130^{\circ} \mathrm{C}$ so that the material then remains amorphous and sticky for hours. The sharp transition fluid/solid can be used to achieve very fast processing speeds. In order to obtain this it is better to melt the material right behind the filling zone and to lower its temperature towards the die. The typical viscosity for this kind of materials is similar to PP with a MFI: $30-40 \mathrm{~g} / 10 \mathrm{~min}$.

\subsection{Pre-cleaning screw and barrel}

As most materials left over in the machine after the last run have high viscosity at $130^{\circ} \mathrm{C}$, they will not be displaced by the low viscous PHB. Such materials can be replaced by adding a coloured batch of a low melting temperature polymer such as PCL (polycaprolactone) or a high MFI PP.

\subsection{Drying}

All PHB based resins contain bound water and not only surface bound water. It is necessary to dry the pellets. Best results are obtained in dry air dryers e.g. for over $2 \mathrm{~h}$ at $80^{\circ} \mathrm{C}$. The pellets regain the original humidity within 30 minutes after they are removed from the dryer.

\section{Processing techniques and conditions}

PHAs can be processed mainly via injection moulding, extrusion and extrusion bubbles into films and hollow bodies.

The thermal, rheological, mechanical and barrier properties of PHBV from various manufacturers were characterized with different valerate contents and molecular weights [67]. The use of co-polymers were chosen in order to improve the flexibility for potential packaging applications, it leads to decrease of the glass transition and melting temperatures. In addition, the HV broadens the processing window since there is improved melt stability at lower processing temperatures. They have observed that the complex viscosity decreased with increasing temperature due to a decrease in molecular weights of the samples. These results suggest that processing the co-polymer below $160^{\circ} \mathrm{C}$ would be beneficial with low screw speed. The mechanical results indicate all PHBV materials had high elastic modulus and flexural strength with low tensile strength and elongation at break. The water vapour transmission rate (WVTR) results indicated the polymer to be very hydrophilic, resulting in higher water transmission rates. The difference in valerate 
content showed two melting transitions for noncommercially available PHBV co-polymers (Aldrich 5, 12 and Tianan 20\%), suggesting an immiscible blend between the PHB homo-polymer and HV comonomer. However, the thermogravimetric analysis (TGA) curves showed minimal separation between the PHB homo-polymer and PHV plasticizing units. The rheological data showed that the Tianan 5\% polymer was thermally stable in the melting temperatures. However, Aldrich 5, 12\% and Tianan 20\% PHBV polymers were thermally unstable at temperatures higher than $160^{\circ} \mathrm{C}$. This instability can be attributed to the breakdown of the polymer chain via the random chain scission process, resulting in lower molecular weight that led to decreasing complex viscosity at higher testing temperatures. The PHBV materials were brittle with high elastic modulus and low tensile strength, thus making it a strong and hard material. In addition, commercially available Tianan $5 \%$ had higher modulus of elasticity, while lower tensile strength and elongation at break compared to conventional thermoplastic used for packaging. Moreover, the water vapour transmission rate was very high compared to thermoplastic used for packaging, which is due to the wide range of processing conditions, HV units, and molecular weights.

The barrier properties of PHA are also important, the WVTR and Oxygen Transmission rate (OTR) for PHA compared with other polymers are included in Table 2.

A series of resorbable polyhydroxyacids by size exclusion chromatography (SEC), viscosity measurements, and differential scanning calorimetry (DSC) in order to understand the effect of the injection moulding process on the molecular weight and thermal properties of the polymers [68]. The studied polymers were polylactides (PLA), polyhydroxybutyrate (PHB) and poly-hydroxybutyrate-co-valerate $(\mathrm{PHB} / \mathrm{VA})(5-22 \%$ VA content). All polylactides underwent extensive degradation, in the range of $50-88 \%$, and an increase in molecular weight distribution (MWD) following injection moulding

Table 2. Barrier properties (water and oxygen) of PHA and other polymers

\begin{tabular}{|l|c|c|c|c|c|}
\hline Permeant & PHA & LDPE & HDPE & PET & Nylon \\
\hline Water & $5-19$ & 1.2 & 0.5 & 1.3 & 25 \\
\hline Oxygen & $23-29$ & $250-840$ & $30-250$ & 5 & 3 \\
\hline
\end{tabular}

WVTR in g-mil $\left(100 \mathrm{~cm}^{2}\right.$-day) at $38^{\circ} \mathrm{C}, 90 \% \mathrm{RH}$

$\mathrm{O}_{2}$ in cc-mil $\left(100 \mathrm{~cm}^{2}\right.$-day) at $25^{\circ} \mathrm{C} 0 \% \mathrm{RH}$ at temperatures ranging from 130 to $215^{\circ} \mathrm{C}$. In contrast to the polylactides, the decrease in molecular weight of the PHB and PHB/VA polymers after injection moulding at temperatures from 135 to $160^{\circ} \mathrm{C}$ was less drastic, in the range of $4-53 \%$. This was accompanied by a decrease of the MWD. No evidence for low molecular weight non-volatile degradation products was observed. Injection moulding led to a decrease in the melting temperature and the heat of melting of PLA. Conversely, the moulding process did not significantly affect the melting temperature and heat of melting of polyhydroxybutyrate/valerates.

Although the incorporation of nanoclay could be interesting in order to improve the properties of PHB and blends, their effect on the processing, degradation and, as such, final molecular weight has to be taken into account.

As reported in [69], the thermal- and thermo-mechanical degradation of the PHB and PHBV, in the presence of ammonium surfactants, commonly used as clay organo-modifiers. TGA degradation data of PHBV demonstrated that all surfactants have an effect on the polymer degradation and that this effect was more pronounced when the initial molecular weight of the polymer was low; indicating that the degradation mechanisms of both PHBV and the surfactant in the blend are interdependent and that the influence depends on the specific surfactant. The same conclusions were found by analysing the thermo-mechanical behaviour and, in all cases, the effect of surfactants is higher for neat PHBV. By studying the molecular weight after processing, they analysed on the one hand the degradation effect of each surfactant with $\mathrm{S}-\mathrm{Bz}$ appearing as the most degrading surfactant. On the other hand, as the molecular weight decreased, the torque values were reduced. Interesting results regarding thermomechanical behaviour of some systems (PHBV + S-EtOH and PHBV4 + S-EtOH) were found because the torque, and thus the shear rate, was stable during the first 10 minutes of processing while the decrease in the molecular weight was limited. Therefore, this surfactant seems the most appropriate to prepare PHBV-based nanocomposites with organomodified clays exhibiting an adequate compromise between high shear rate, required to exfoliate layered silicates, and limited polymer degradation that could affect the material properties. 


\section{Comparison of the biodegradation of PHA with other biopolymers}

PHAs are degraded upon exposure to soil, compost, or marine sediment. PHB can be biodegraded in both aerobic and anaerobic environments, without forming any toxic products [70]. Biodegradation is dependent on a number of factors such as microbial activity, moisture, temperature, $\mathrm{pH}$ of the environment, and the exposed surface area, molecular weight polymer composition, nature of monomer unit and crystallinity ([71, 72]). PHB, polypropiolactone (PPL) and PCL degraders are widely distributed in different environments ([73-75]). Majority of the strains that are able to degrade PHB belong to different taxa such as Gram-positive and Gramnegative bacteria, Streptomyces and fungi [74]. It has been reported that 39 bacterial strains of the classes Firmicutes and Proteobacteria can degrade PHB, PCL, and PBS, but not PLA [75]. The population of aliphatic polymer-degrading microorganisms in different ecosystems was found to be in the following order: PHB $=$ PCL $>$ PBS $>$ PLA [70].

Copolymers containing PHB monomer units have been found to be degraded more rapidly than either PHB or 3HB-co-3HV copolymers.

Chowdhury reported for the first time the PHBdegrading microorganisms from Bacillus, Pseudomonas and Streptomyces species [76] From then on, several aerobic and anaerobic PHB-degrading microorganisms have been isolated from soil (Pseudomonas lemoigne, Comamonas sp. Acidovorax faecalis, Aspergillus fumigates and Variovorax paradoxus), activated and anerobic sludge (Alcaligenes faecalis, Pseudomonas, Illyobacter delafieldi), seawater and lakewater (Comamonas testosterone, Pseudomonas stutzeri) [77]. Microorganisms secrete enzymes that break down the polymer into its molecular building blocks, called hydroxyacids, which are utilized as a carbon source for growth. The principal enzyme for the degradation of PHB and oligomers derived from the polymer is PHB depolymerise. Studies on the extracellular PHB depolymerase of Alcaligenes faecalis have indicated it to be an endo-type hydrolase. Other prominent organisms in which PHB depolymerase has been identified and worked upon are Rhodospirillum rubrum, B. megaterium, A. beijerinckii, and Pseudomonas lemoignei [78].

The percentage of PHB-degrading microorganisms in the environment was estimated to be $0.5-9.6 \%$ of the total colonies [75]. Majority of the PHB-degrading microorganisms were isolated at ambient or mesophilic temperatures and very few of them were capable of degrading PHB at higher temperature. Composting at high temperature is one of the most promising technologies for recycling biodegradable plastics and thermophilic microorganisms that could degrade polymers play an important role in the composting process [79]. Thus, microorganisms which are capable of degrading various kinds of polyesters at high temperatures are of interest. A thermophilic Streptomyces sp. Isolated from soil can degrade not only PHB but also PES, PBS and poly[oligo (tetramethylene succinate)-co-(tetramethylene carbonate)] (PBS/C). This actinomycete has higher PHBdegrading activity than thermotolerant and thermophilic Streptomyces strains from culture collections [80]. A thermotolerant Aspergillus sp. was able to degrade $90 \%$ of PHB film after five days cultivation at $50^{\circ} \mathrm{C}$ [81] Furthermore, several thermophilic polyester degrading actinomycetes were isolated from different ecosystems. Out of 341 strains, 31 isolates were PHB, PCL and PES degraders and these isolates were identified as members of the genus Actinomadura, Microbispora, Streptomyces, Thermoactinomyces and Saccharomonospora [82]. The miscibility, morphology and biodegradability of PHB blends with PCL, polybutylene adipate (PBA), and poly(vinyl acetate) (PVAc) were investigated. PHB/PCL and PHB/PBA blends were immiscible in the amorphous state while PHB/PVAc are miscible. Enzymatic degradation of these blends was carried out using PHB depolymerase from Alcaligenes feacalis T1. Results showed that the weight loss of the blends decreased linearly with increase in the amount of PBA, PVAc or PCL [64].

In blends of PHB/PLA the spherulites of the blends decreased with an increase in the content of the PLA and the rate of enzymatic surface erosion also decreased with increasing PLA content in the blend. It was evident that polymer blends containing PHB usually showed improved properties and biodegradability when compared with pure PHB [83].

Biodegradation of PHA under aerobic conditions results in carbon dioxide and water, whereas in anaerobic conditions the degradation products are carbon dioxide and methane. PHA are compostable over a wide range of temperatures, even at a maximum of around $60^{\circ} \mathrm{C}$ with moisture levels at $55 \%$. Studies have shown that $85 \%$ of PHA was degraded 
in seven weeks ([84, 85]). PHA has been reported to degrade in aquatic environments (Lake Lugano, Switzerland) within 254 days even at temperatures not exceeding $6^{\circ} \mathrm{C}$ [84].

\section{Market aspects of polyhydroxyalkanoates 6.1. Industrial production of polyhydroxyalkanoates}

In the industrial production of PHA, the polyester is extracted and purified from the bacteria by optimising the conditions of microbial fermentation of sugar or glucose. In the 1980s, Imperial Chemical Industries developed poly (3-hydroxybutyrate-co3-hydroxyvalerate) obtained via fermentation that was named 'Biopol'. It was sold under the name 'Biopol' and distributed in the U.S. by Monsanto and later Metabolix.

As a raw material for the fermentation, carbohydrates such as glucose and sucrose can be used, but also vegetable oil or glycerine from biodiesel production. Researchers in industry are working on methods with which transgenic crops will be developed that express PHA synthesis routes from bacteria to produce PHA as energy storage in their tissues [21]. Different research efforts also deal with the valorisation of wastes as non-food competing sources for cultivating a range of bacteria with the purpose of obtaining PHA biopolymers with improved sustainability. For example ongoing research deals with the growth of cyanobacteria in olive mill wastewaters to produce PHAs including their possible genetic modification to increase the yield in PHA [2]. Another group of researchers at Micromidas is working to develop methods of producing PHA from municipal wastewater. Figure 8 shows the biodegradation of PHB on the marine environment compared with other polymers.

\subsection{Commercial products}

Commercial ventures scaling up PHA production using fermentation processes include Telles, USA; Biomer Biotechnology Co., Germany; PHB Industrial, Brazil; Mitsubishi Gas Chemical, Japan; Kaneka, Japan; Biomatera, Italy; Jiangsu Nantian Group, China; Tianan Biologic Material, China; and Lianyi Biotech, China.

Table 3 summarises the most known commercially available polyhydroxyalkanoates.

The thermal and mechanical properties of materials described in the previous table, obtained from their respective technical datasheets, are summarised in Table 4.

Table 3. Commercial polyhydroxyalkanoates: names, producer, origin and products

\begin{tabular}{|c|c|c|c|}
\hline Commercial name & Producer & Country & Product \\
\hline Biomer & Biomer & Germany & $\begin{array}{l}\text { Biomer P209 } \\
\text { Biomer P226 } \\
\text { Biomer P240 }\end{array}$ \\
\hline Minerv-PHA & Bio-on & Italy & MINERV-PHA ${ }^{\mathrm{TM}}$ \\
\hline Biogreen & Mitshubishi Gas & Japan & Biogreen \\
\hline Biocycle & PHB Industrial & Brazil & $\begin{array}{l}\text { BIOCYCLE 1000 } \\
\text { BIOCYCLE 18BC-1 } \\
\text { BIOCYCLE 189C-1 } \\
\text { BIOCYCLE 189D-1 }\end{array}$ \\
\hline Ecogen & $\begin{array}{l}\text { Tianan Biological Material Poly- } \\
\text { one }\end{array}$ & China & $\begin{array}{l}\text { ENMAT Y1000 } \\
\text { ENMAT Y1000P } \\
\text { ENMAT Y3000 } \\
\text { ENMAT Y3000P }\end{array}$ \\
\hline Mirel & Metabolix & USA & $\begin{array}{l}\text { Mirel P4001 } \\
\text { Mirel P4010 } \\
\text { Mirel P5001 } \\
\text { Mirel P5004 } \\
\text { Mirel M2100 } \\
\text { Mirel M2200 } \\
\text { Mirel M4100 }\end{array}$ \\
\hline Nodax & P\&G Chemicals & USA/Japan & Nodax $^{\mathrm{TM}}$ \\
\hline Metabolix & Telles LLC & USA & $\begin{array}{l}\text { Mvera }^{\mathrm{TM}} \text { B5011 } \\
\text { Mvera }^{\mathrm{TM}} \text { B5010 }\end{array}$ \\
\hline Jiangsu Nantian & Jiangsu Nantian Group & China & $\mathrm{P}(3 \mathrm{HB})$ \\
\hline Goodfellow & Goodfellow Cambridge Ltd & UK & $\begin{array}{l}\text { Polyhydroxyalkaonate - Biopolymer (PHA) } \\
\text { Polyhydroxybutyrate/Polyhydroxyvalerate 12\%- } \\
\text { Biopolymer (PHB88/PHV12) }\end{array}$ \\
\hline Tepha [86] & Tepha Inc & USA & $\mathrm{P}(4 \mathrm{HB})$ \\
\hline
\end{tabular}


Table 4. Thermal and mechanical properties of commercial polyhydroxyalkanoates

\begin{tabular}{|c|c|c|c|c|c|c|}
\hline \multirow[t]{2}{*}{ Product } & \multicolumn{3}{|c|}{ Thermal properties } & \multicolumn{3}{|c|}{ Mechanical Properties } \\
\hline & $\begin{array}{c}\mathbf{T}_{\mathbf{m}} \\
{\left[{ }^{\circ} \mathbf{C}\right]}\end{array}$ & $\begin{array}{c}\mathbf{X}_{\mathbf{c r}} \\
{[\%]}\end{array}$ & $\begin{array}{c}\mathbf{T}_{\mathbf{g}} \\
{\left[{ }^{\circ} \mathbf{C}\right]}\end{array}$ & $\begin{array}{c}\mathbf{E} \\
{[\mathbf{G P a}]}\end{array}$ & $\begin{array}{c}\sigma \\
{[\mathrm{MPa}]}\end{array}$ & $\begin{array}{c}\varepsilon \\
{[\%]}\end{array}$ \\
\hline Biomer P209 & - & $30-40$ & - & $0.84-1.20$ & $15-20$ & $600-1200$ \\
\hline Biomer P226 & - & $60-70$ & - & $1.14-1.90$ & $24-27$ & 6-9 \\
\hline Biomer P240 & - & $60-70$ & - & $\approx 1.85$ & 28 & $\approx 11$ \\
\hline BIOCYCLE 1000 & $170-175$ & - & 117 & 2.2 (Flex) & 32 & 4.0 \\
\hline BIOCYCLE 18BC-1 & $165-170$ & - & 117 & 2.4 (Flex) & 25 & 2.2 \\
\hline BIOCYCLE 189C-1 & $165-170$ & - & 121 & 2.6 (Flex) & 30 & 2.2 \\
\hline BIOCYCLE 189D-1 & $165-170$ & - & 125 & 3.8 (Flex) & 36 & 2.0 \\
\hline ENMAT Y1000 & $170-176$ & - & - & $2.8-3.5$ & 39 & 2 \\
\hline $\begin{array}{l}\text { Mirel P4001 } \\
\text { Mirel P4010 } \\
\text { Mirel P5001 } \\
\text { Mirel P5004 } \\
\text { Mirel M2100 } \\
\text { Mirel M2200 } \\
\text { Mirel M4100 }\end{array}$ & $\begin{array}{c}- \\
- \\
- \\
170 \\
170 \\
165-170 \\
160-170 \\
164-166\end{array}$ & $\begin{array}{c}- \\
- \\
- \\
- \\
- \\
30-60 \\
40-60 \\
27-45\end{array}$ & $\begin{array}{l}110 \\
- \\
- \\
- \\
- \\
- \\
- \\
-\end{array}$ & $\begin{array}{c}1.90 \text { (Flex) } \\
1.45 \text { (Flex) } \\
0.30-0.32 \\
0.3-0.4 \\
- \\
- \\
- \\
-\end{array}$ & $\begin{array}{c}20 \\
10 \\
20 \\
25-30 \\
- \\
- \\
- \\
-\end{array}$ & $\begin{array}{c}5 \\
10 \\
404-463 \\
400-500 \\
- \\
- \\
- \\
-\end{array}$ \\
\hline
\end{tabular}

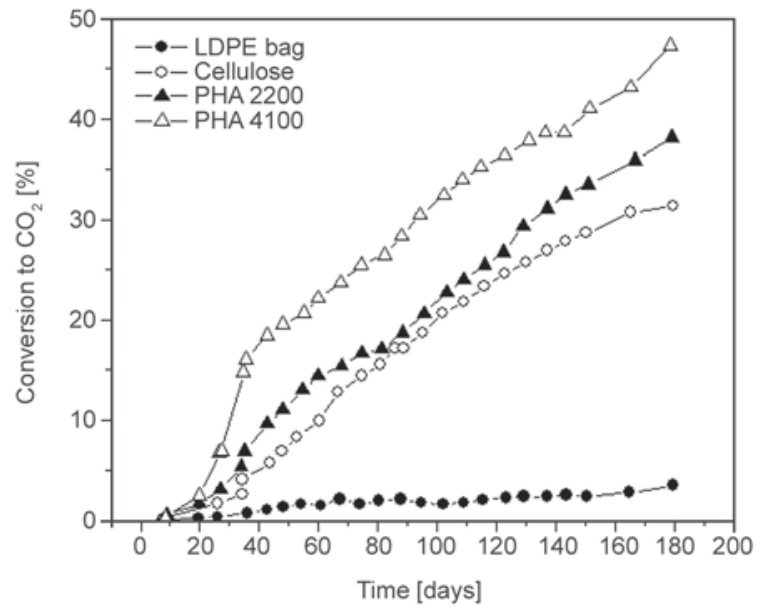

Figure 8. Biodegradation of PHB on the marine environment compared with other polymers. Faster biodegradation for PHA can be observed.

\section{Conclusions}

Overall, the reviewed literature highlights PHA is a very promising polymer for a wide range of applications. For example, it has better barrier properties (OTR and WVTR) and mechanical strength than other more widespread bioplastics such as PLA. In spite of its intrinsic brittleness, a lot of progress reported here has been made recently through the formulation of PHB with tailored additives and blends leading to greatly improved mechanical profiles, as well as suitable processability via extrusion or injection moulding, among others. These advances will improve its capacity to penetrate markets such as food packaging. Nevertheless, limitations still persist such as the elevated cost of commercial PHA, limited market availability and the use of refined/ food competing feedstock. As such different research studies are ongoing regarding the improvement of the yield of PHA by e.g. genetic modification of the bacteria or the use of waste for their growth. Finally, further improvements could allow even more flexible grades of PHAs or transparent ones through the control of its crystallisation to be obtained (Table 5). This range of interesting properties and processability open up a bright future for PHB in applications ranging from surgical sutures, tissue engineering [87] and agricultural foils to packaging for the storage of food products [88]. Like PVC and PET, it exhibits good barrier properties [89], and can be used in the packaging industry as a biodegradable plastic for contributing to solving environmental pollution problems [90]. Due to these interesting properties, PHB is expected to be a good candidate to substitute [91] PP and PE, but also PET in certain applications.

In medicine, PHB is compatible with the blood and tissues of mammals. The monomer of PHB is a normal metabolic in the human blood. As the body reabsorbs PHB it could be used as a surgical implant, in surgery, as seam threads for the healing of wounds and blood vessels. In pharmacology, PHB can be used as microcapsules in therapy or as materials for cell and tablet packaging. It can also be used for packaging applications for deep drawing articles in the food industry, for example, bottles, laminated foils, fishnets, flowerpots, sanitary goods, fast foods, disposable cups, agricultural foils and fibres in textiles. 
Table 5. Challenge and Prospects of PHAs

\begin{tabular}{|c|c|}
\hline PHAS challenges & PHAs prospects \\
\hline High cost of production and extraction & $\begin{array}{l}\text { - Reduction in cost related to the use of substrate for bacteria growth coming from by prod- } \\
\text { ucts or waste materials. } \\
\text { - Increase PHAs production by use of mixed culture or modified bacteria or microalgae. } \\
\text { - Optimisation of PHA extraction processes. }\end{array}$ \\
\hline Quality of PHA & - Optimisation of the quality and uniformity of PHAs produced in mixed culture. \\
\hline Mechanical properties & $\begin{array}{l}\text { - Better understanding of PHAs kinetics of crystallization and proper choice of additives } \\
\text { (nucleating agents, plasticizers) to achieve stability in mechanical properties, and improve- } \\
\text { ment in elongation at break. }\end{array}$ \\
\hline Production of blends and composites & $\begin{array}{l}\text { - Optimisation in the use of PHAs in blends with other biodegradable polymers achieving a } \\
\text { reduction in cost of the final product while still maintaining the outstanding properties of } \\
\text { PHAs in terms of barrier properties, Modulus, high biodegrability in different environments. }\end{array}$ \\
\hline Blends with natural additives & $\begin{array}{l}\text { - PHAs in processing are very sensitve to water presence, but proper drying of natural addi- } \\
\text { tives and proper choice of compatibilizers is promising for the preparation of blends of } \\
\text { PHAs and natural polymers (starch, proteins, etc.) which can achieve the production of plas- } \\
\text { tic items with high biodegradability, for example also in marine environment. }\end{array}$ \\
\hline
\end{tabular}

Nevertheless, further improvements are still needed to allow a broader market introduction of PHAs. One of the main limitations in the application of PHB for the production of single use items is based on its relatively high cost (7-10 Euro/kg) when compared to other polymers. Further investigations and efforts must be undertaken by scientists in order to reduce the production costs of these PHAs and increase the industrial sustainability and commercialisation of PHAs [92]. The use of natural fillers with high availability and low cost allows the production of bio-composite more suited for their application in, for example, packaging and agriculture. In addition, the use of waste feedstock for the culture of the microorganisms accumulating PHAs is also prompted as a route to lead to their greater economic viability and sustainability.

\section{Acknowledgements}

Authors acknowledge the financial support from the European Community's Seventh Framework Programme (FP7/ 2007-2013) under NMP grant agreement No. 280604.

\section{References}

[1] Bugnicourt E., Schmid M., Nerney O. M., Wildner J., Smykala L., Lazzeri A., Cinelli P.: Processing and validation of whey-protein-coated films and laminates at semi-industrial scale as novel recyclable food packaging materials with excellent barrier properties. Advances in Materials Science and Engineering, 2013, 496207/1496207/10 (2013).

DOI: $10.1155 / 2013 / 496207$
[2] Cinelli P., Lazzeri A., Anguillesi I., Bugnicourt E.: OliPHA a novel and efficient method for the production of polyhydroxyalkanoate polymer-based packaging from olive oil waste water. in 'Proceedings of $3^{\text {rd }}$ International Conference on industrial and hazardous waste management. Chania, Crete, Greece' p8 (2012).

[3] Lepoittevin B., Devalckenaere M., Pantoustier N., Alexandre M., Kubies D., Calberg C., Jérôme R., Dubois P.: Poly( $\varepsilon$-caprolactone)/clay nanocomposites prepared by melt intercalation: Mechanical, thermal and rheological properties. Polymer, 43, 4017-4023 (2002). DOI: $10.1016 / \mathrm{S} 0032-3861(02) 00229-\mathrm{X}$

[4] Biron M.: The plastics industry: Economic overview. in 'Thermoplastics and thermoplastic composites' (ed.: Biron M.) William Andrew Publishing, Norwich, 31-153 (2013).

[5] Dikgang J., Leiman A., Visser M.: Analysis of the plastic-bag levy in South Africa. Resources, Conservation and Recycling, 66, 59-65 (2012).

DOI: $10.1016 /$ j.resconrec.2012.06.009

[6] Meneses J., Corrales C. M., Valencia M.: Synthesis and characterization of biodegradable polymers from cassava starch (in Spanish). Revista EIA, 8, 57-67 (2007).

[7] Mutha N. H., Patel M. K., Premnath V.: Plastics materials flow analysis for India. Resources, Conservation and Recycling, 47, 222-244 (2006).

DOI: $10.1016 /$ j.resconrec.2005.09.003

[8] Mulder K. F.: Sustainable consumption and production of plastics? Technological Forecasting and Social Change, 58, 105-124 (1998). DOI: $10.1016 / \mathrm{S} 0040-1625(97) 00129-7$

[9] Varsha Y. M., Savitha R.: Overview on polyhydroxyalkanoates: A promising biopol. Journal of Microbial and Biochemical Technology, 3, 99-105 (2011). DOI: $10.4172 / 1948-5948.1000059$

[10] Dawes E. A., Senior P. J.: The role and regulation of energy reserve polymers in micro-organisms. Advances in Microbial Physiology, 10, 135-266 (1973). 
[11] Laycock B., Halley P., Pratt S., Werker A., Lant P.: The chemomechanical properties of microbial polyhydroxyalkanoates. Progress in Polymer Science, 38, 536583 (2013).

DOI: 10.1016/j.progpolymsci.2012.06.003

[12] Noda I., Marchessault R. H., Terada M.: Polymer data handbook. Oxford University Press, London (1999).

[13] El-Hadi A., Schnabel R., Straube E., Müller G., Henning S.: Correlation between degree of crystallinity, morphology, glass temperature, mechanical properties and biodegradation of poly (3-hydroxyalkanoate) phas and their blends. Polymer Testing, 21, 665-674 (2002). DOI: $10.1016 / \mathrm{S} 0142-9418(01) 00142-8$

[14] de Köning G. J. M., Lemstra P. J.: Crystallization phenomena in bacterial poly[(R)-3-hydroxybutyrate]: 2 . Embrittlement and rejuvenation. Polymer, 34, 40894094 (1993).

DOI: 10.1016/0032-3861(93)90671-V

[15] Holmes P. A.: Applications of PHB - a microbially produced biodegradable thermoplastic. Physics in Technology, 16, 32-41 (1985).

DOI: $10.1088 / 0305-4624 / 16 / 1 / 305$

[16] Di Lorenzo M. L., Raimo M., Cascone E., Martuscelli E.: Poly(3-hydroxybutyrate)-based copolymers and blends: Influence of a second component on crystallization and thermal behavior. Journal of Macromolecular Science Part B: Physics, 40, 639-667 (2001). DOI: $10.1081 / \mathrm{mb}-100107554$

[17] Androsch R.: Surface structure of folded-chain crystals of poly ( $R$-3-hydroxybutyrate) of different chain length. Polymer, 49, 4673-4679 (2008).

DOI: 10.1016/j.polymer.2008.08.026

[18] Wunderlich B.: Reversible crystallization and the rigid-amorphous phase in semicrystalline macromolecules. Progress in Polymer Science, 28, 383-450 (2003). DOI: $10.1016 / \mathrm{S} 0079-6700(02) 00085-0$

[19] Di Lorenzo M. L., Gazzano M., Righetti M. C.: The role of the rigid amorphous fraction on cold crystallization of poly(3-hydroxybutyrate). Macromolecules, 45, 5684-5691 (2012). DOI: $10.1021 / \mathrm{ma3} 010907$

[20] Schick C., Wurm A., Mohamed A.: Dynamics of reversible melting revealed from frequency dependent heat capacity. Thermochimica Acta, 392-393, $303-$ 313 (2002).

DOI: 10.1016/S0040-6031(02)00116-8

[21] Doi Y., Mukai K., Kasuya K., Yamada K.: Biodegradation of biosynthetic and chemosynthetic polyhydroxyalkanoates. Studies in Polymer Science, 12, 39-51 (1994).

[22] Grassie N., Murray E. J., Holmes P. A.: The thermal degradation of poly(-(D)- $\beta$-hydroxybutyric acid): Part 1 - Identification and quantitative analysis of products. Polymer Degradation and Stability, 6, 47-61 (1984). DOI: 10.1016/0141-3910(84)90016-8
[23] Grassie N., Murray E. J., Holmes P. A.: The thermal degradation of poly(-(D)- $\beta$-hydroxybutyric acid): Part 2 - Changes in molecular weight. Polymer Degradation and Stability, 6, 95-103 (1984). DOI: 10.1016/0141-3910(84)90075-2

[24] Mohanty A. K., Misra M., Drzal L. T.: Sustainable biocomposites from renewable resources: Opportunities and challenges in the green materials world. Journal of Polymers and the Environment, 10, 19-26 (2002).

DOI: 10.1023/a:1021013921916

[25] Erceg M., Kovačić T., Klarić I.: Thermal degradation of poly(3-hydroxybutyrate) plasticized with acetyl tributyl citrate. Polymer Degradation and Stability, 90, 313-318 (2005).

DOI: $10.1016 /$ j.polymdegradstab.2005.04.048

[26] Di Lorenzo M. L., Sajkiewicz P., La Pietra P., Gradys A.: Irregularly shaped DSC exotherms in the analysis of polymer crystallization. Polymer Bulletin, 57, 713721 (2006).

DOI: $10.1007 / \mathrm{s} 00289-006-0621-4$

[27] Donth E. J.: Relaxation and thermodynamics in polymers. Akademie Verlag, Berlin (1992).

[28] Scandola M., Ceccorulli G., Doi Y.: Viscoelastic relaxations and thermal properties of bacterial poly(3hydroxybutyrate-co-3-hydroxyvalerate) and poly(3hydroxybutyrate-co-4-hydroxybutyrate). International Journal of Biological Macromolecules, 12, 112-117 (1990).

DOI: 10.1016/0141-8130(90)90062-F

[29] Mitomo H., Barham P. J., Keller A.: Temperature dependance of mechanical properties of poly( $\beta$-hydroxybutyrate- $\beta$-hydroxyvalerate). Polymer Communications, 29, 112-115 (1988).

[30] Zhang L., Deng X., Zhao S., Huang Z.: Biodegradable polymer blends of poly(3-hydroxybutyrate) and hydroxyethyl cellulose acetate. Polymer, 38, 6001-6007 (1997).

DOI: $10.1016 / \mathrm{S} 0032-3861(97) 00158-4$

[31] Ahmed T., Marçal H., Lawless M., Wanandy N. S., Chiu A., Foster L. J. R.: Polyhydroxybutyrate and its copolymer with polyhydroxyvalerate as biomaterials: Influence on progression of stem cell cycle. Biomacromolecules, 11, 2707-2715 (2010).

DOI: $10.1021 / \mathrm{bm} 1007579$

[32] Qiu Y-Z., Han J., Guo J-J., Chen G-Q.: Production of poly(3-hydroxybutyrate-co-3-hydroxyhexanoate) from gluconate and glucose by recombinant Aeromonas hydrophila and Pseudomonas putida. Biotechnology Letters, 27, 1381-1386 (2005). DOI: $10.1007 / \mathrm{s} 10529-005-3685-6$

[33] Caballero K. P., Karel S. F., Register R. A.: Biosynthesis and characterization of hydroxybutyrate-hydroxycaproate copolymers. International Journal of Biological Macromolecules, 17, 86-92 (1995). DOI: $10.1016 / 0141-8130(95) 93522-\mathrm{Y}$ 
[34] Zhao K., Deng Y., Chen J. C., Chen G-Q.: Polyhydroxyalkanoate (PHA) scaffolds with good mechanical properties and biocompatibility. Biomaterials, 24, 1041-1045 (2003). DOI: 10.1016/S0142-9612(02)00426-X

[35] Avella M., Martuscelli E., Raimo M.: Review: Properties of blends and composites based on poly(3-hydroxy) butyrate (PHB) and poly(3-hydroxybutyrate-hydroxyvalerate) (PHBV) copolymers. Journal of Materials Science, 35, 523-545 (2000). DOI: $10.1023 / \mathrm{A}: 1004740522751$

[36] Scaffaro R., Dintcheva N. T., Marino R., La Mantia F. P.: Processing and properties of biopolymer/polyhydroxyalkanoates blends. Journal of Polymers and the Environment, 20, 267-272 (2012). DOI: 10.1007/s10924-011-0385-2

[37] Innocentini-Mei L. H., Bartoli J. R., Baltieri R. C.: Mechanical and thermal properties of poly(3-hydroxybutyrate) blends with starch and starch derivatives. Macromolecular Symposia, 197, 77-88 (2003). DOI: $10.1002 /$ masy.200350708

[38] Shen L., Haufe J., Patel M.: Product overview and market projection of emerging bio-based plastics. PRO-BIP 2009, Final report, Utrecht (2009).

[39] Hong S-G., Hsu H-W., Ye M-T.: Thermal properties and applications of low molecular weight polyhydroxybutyrate. Journal of Thermal Analysis and Calorimetry, 111, 1243-1250 (2013).

DOI: $10.1007 / \mathrm{s} 10973-012-2503-3$

[40] Parra D. F., Fusaro J., Gaboardi F., Rosa D. S.: Influence of poly (ethylene glycol) on the thermal, mechanical, morphological, physical-chemical and biodegradation properties of poly (3-hydroxybutyrate). Polymer Degradation and Stability, 91, 1954-1959 (2006). DOI: $10.1016 /$ j.polymdegradstab.2006.02.008

[41] Rodrigues J. A. F. R., Parra D. F., Lugão A. B.: Crystallization on films of PHB/PEG blends. Journal of Thermal Analysis and Calorimetry, 79, 379-381 (2005). DOI: 10.1007/s10973-005-0069-Z

[42] Wang L., Zhu W., Wang X., Chen X., Chen G-Q., Xu K.: Processability modifications of poly(3-hydroxybutyrate) by plasticizing, blending, and stabilizing. Journal of Applied Polymer Science, 107, 166-173 (2008). DOI: $10.1002 /$ app. 27004

[43] de O. Patrício P. S., Pereira F. V., dos Santos M. C., de Souza P. P., Roa J. P. B., Orefice R. L.: Increasing the elongation at break of polyhydroxybutyrate biopolymer: Effect of cellulose nanowhiskers on mechanical and thermal properties. Journal of Applied Polymer Science, 127, 3613-3621 (2013).

DOI: $10.1002 /$ app.37811

[44] Modi S. J.: Assessing the feasibility of poly-(3hydroxybutyrate-co-3-hydroxyvalerate) (PHBV) and poly-(lactic acid) for potential food packaging applications. PhD Thesis, Ohio State University, Colombus (2010).
[45] Zhu C., Nomura C. T., Perrotta J. A., Stipanovic A. J., Nakas J. P.: The effect of nucleating agents on physical properties of poly-3-hydroxybutyrate (PHB) and poly3-hydroxybutyrate-co-3-hydroxyvalerate (PHB-co-HV) produced by Burkholderia cepacia ATCC 17759. Polymer Testing, 31, 579-585 (2012).

DOI: $10.1016 /$ j.polymertesting.2012.03.004

[46] Corrêa M. C. S., Branciforti M. C., Pollet E., Agnelli J. A. M., Nascente P. A. P., Avérous L.: Elaboration and characterization of nano-biocomposites based on plasticized poly(hydroxybutyrate-co-hydroxyvalerate) with organo-modified montmorillonite. Journal of Polymers and the Environment, 20, 283-290 (2012).

DOI: $10.1007 / \mathrm{s} 10924-011-0379-0$

[47] Whitehouse R. S.: Toughened polyhydroxyalkanoate compositions. WO 2011031558 A3, World Patent (2011).

[48] Harasawa I., Hariki Y., Maeda K., Nakamura K.: Method for cultivating algae and a covering material used therefor. U.S. Patent 4235043 A, USA (1980).

[49] Yu L., Dean K., Li L.: Polymer blends and composites from renewable resources. Progress in Polymer Science, 31, 576-602 (2006).

DOI: $10.1016 /$ j.progpolymsci.2006.03.002

[50] Scandola M., Ceccorulli G., Pizzoli M.: Miscibility of bacterial poly(3-hydroxybutyrate) with cellulose esters. Macromolecules, 25, 6441-6446 (1992).

DOI: $10.1021 / \mathrm{ma} 00050 \mathrm{a} 009$

[51] Scandola M., Focarete M. L., Adamus G., Sikorska W., Baranowska I., Świerczek S., Gnatowski M., Kowalczuk M., Jedliński Z.: Polymer blends of natural poly(3-hydroxybutyrate-co-3-hydroxyvalerate) and a synthetic atactic poly(3-hydroxybutyrate). Characterization and biodegradation studies. Macromolecules, 30, 2568-2574 (1997).

DOI: $10.1021 / \mathrm{ma} 961431 \mathrm{y}$

[52] Choi H. J., Kim J., Jhon M. S.: Viscoelastic characterization of biodegradable poly(3-hydroxybutyrate-co3-hydroxyvalerate). Polymer, 40, 4135-4138 (1999). DOI: 10.1016/S0032-3861(98)00627-2

[53] Avella M., Martuscelli E., Raimo M.: The fractionated crystallization phenomenon in poly(3-hydroxybutyrate)/poly(ethylene oxide) blends. Polymer, 34, 3234-3240 (1993). DOI: 10.1016/0032-3861(93)90396-R

[54] Gassner F., Owen A. J.: Physical properties of poly( $\beta$ hydroxybutyrate)-poly( $\varepsilon$-caprolactone) blends. Polymer, 35, 2233-2236 (1994).

DOI: 10.1016/0032-3861(94)90258-5

[55] Abe H., Doi Y., Kumagai Y.: Synthesis and characterization of poly[ $(R, S)$-3-hydroxybutyrate- $b$-6-hydroxyhexanoate] as a compatibilizer for a biodegradable blend of poly[(R)-3-hydroxybutyrate $]$ and poly(6hydroxyhexanoate). Macromolecules, 27, 6012-6017 (1994).

DOI: $10.1021 / \mathrm{ma} 00099 \mathrm{a} 012$ 
[56] Choi H. J., Kim J. H., Kim J., Park S. H.: Mechanical spectroscopy study on biodegradable synthetic and biosynthetic aliphatic polyesters. Macromolecular Symposia, 119, 149-155 (1997).

DOI: $10.1002 /$ masy. 19971190115

[57] Paglia E. D., Beltrame P. L., Canetti M., Seves A., Marcandalli B., Martuscelli E.: Crystallization and thermal behaviour of poly ( $\mathrm{D}(-)$ 3-hydroxybutyrate)/ poly(epichlorohydrin) blends. Polymer, 34, 996-1001 (1993). DOI: 10.1016/0032-3861(93)90220-5

[58] Sharma R., Ray A. R.: Polyhydroxybutyrate, its copolymers and blends. Journal of Macromolecular Science Part C: Polymer Reviews, 35, 327-359 (1995). DOI: $10.1080 / 15321799508009640$

[59] Duarte M. A. T., Hugen R. G., Sant'Anna Martins E., Pezzin A. P. T., Pezzin S. H.: Thermal and mechanical behavior of injection molded poly(3-hydroxybutyrate)/ poly( $\varepsilon$-caprolactone) blends. Materials Research, 9, 25-28 (2006).

DOI: $10.1590 / \mathrm{S} 1516-14392006000100006$

[60] Ceccorulli G., Pizzoli M., Scandola M.: Effect of a low-molecular-weight plasticizer on the thermal and viscoelastic properties of miscible blends of bacterial poly(3-hydroxybutyrate) with cellulose acetate butyrate. Macromolecules, 26, 6722-6726 (1993).

DOI: $10.1021 / \mathrm{ma} 00077 \mathrm{a} 005$

[61] Pizzoli M., Scandola M., Ceccorulli G.: Crystallization kinetics and morphology of poly(3-hydroxybutyrate)/cellulose ester blends. Macromolecules, 27, 4755-4761 (1994).

DOI: $10.1021 / \mathrm{ma} 00095 \mathrm{a} 016$

[62] Park J. W., Doi Y., Iwata T.: Unique crystalline orientation of poly $[(R)-3$-hydroxybutyrate $] /$ cellulose propionate blends under uniaxial drawing. Macromolecules, 38, 2345-2354 (2005).

DOI: $10.1021 / \mathrm{ma} 0481611$

[63] Gazzano M., Mazzocchetti L., Pizzoli M., Scandola M.: Crystal orientation switching in spherulites grown from miscible blends of poly(3-hydroxybutyrate) with cellulose tributyrate. Journal of Polymer Science Part B: Polymer Physics, 50, 1463-1473 (2012).

DOI: 10.1002/polb.23147

[64] Kumagai Y., Doi Y.: Enzymatic degradation of binary blends of microbial poly(3-hydroxybutyrate) with enzymatically active polymers. Polymer Degradation and Stability, 37, 253-256 (1992).

DOI: 10.1016/0141-3910(92)90167-4

[65] Singh S., Mohanty A. K.: Wood fiber reinforced bacterial bioplastic composites: Fabrication and performance evaluation. Composites Science and Technology, 67, 1753-1763 (2007).

DOI: 10.1016/j.compscitech.2006.11.009

[66] Avérous L., Le Digabel F.: Properties of biocomposites based on lignocellulosic fillers. Carbohydrate Polymers, 66, 480-493 (2006).

DOI: $10.1016 /$ j.carbpol.2006.04.004
[67] Modi S., Koelling K., Vodovotz Y.: Assessment of PHB with varying hydroxyvalerate content for potential packaging applications. European Polymer Journal, 47, 179-186 (2011).

DOI: $\underline{10.1016 / j . e u r p o l y m j .2010 .11 .010}$

[68] Gogolewski S., Jovanovic M., Perren S. M., Dillon J. G., Hughes M. K.: The effect of melt-processing on the degradation of selected polyhydroxyacids: Polylactides, polyhydroxybutyrate, and polyhydroxybutyrate-co-valerates. Polymer Degradation and Stability, 40, 313-322 (1993).

DOI: 10.1016/0141-3910(93)90137-8

[69] Bordes P. H., Pollet E., Avérous L.: Effect of clay organomodifiers on degradation of polyhydroxyalkanoates. Polymer Degradation and Stability, 94, 789796 (2009).

DOI: 10.1016/j.polymdegradstab.2009.01.027

[70] Tokiwa Y., Calabia B. P., Ugwu C. U., Aiba S.: Biodegradability of plastics. International Journal of Molecular Sciences, 10, 3722- 3742 (2009).

DOI: $10.3390 /$ ijms 10093722

[71] Boopathy R.: Factors limiting bioremediation technologies. Bioresource Technology, 74, 63-67 (2000). DOI: $10.1016 / \mathrm{S} 0960-8524(99) 00144-3$

[72] Lee S. Y.: Plastic bacteria? Progress and prospects for polyhydroxyalkanoate production in bacteria. Trends in Biotechnology, 14, 431-438 (1996). DOI: $10.1016 / 0167-7799(96) 10061-5$

[73] Nishida H., Tokiwa Y.: Distribution of poly( $\beta$-hydroxybutyrate) and poly( $\varepsilon$-caprolactone)aerobic degrading microorganisms in different environments. Journal of Environmental Polymer Degradation, 1, 227-233 (1993). DOI: $10.1007 / \mathrm{bf01458031}$

[74] Mergaert J., Swings J.: Biodiversity of microorganisms that degrade bacterial and synthetic polyesters. Journal of Industrial Microbiology, 17, 463-469 (1996). DOI: $\underline{10.1007 / \mathrm{bf0} 01574777}$

[75] Suyama T., Tokiwa Y., Ouichanpagdee P., Kanagawa T., Kamagata Y.: Phylogenetic affiliation of soil bacteria that degrade aliphatic polyesters available commercially as biodegradable plastics. Applied and Environmental Microbiolology, 64, 5008-5011 (1998).

[76] Chowdhury A. A.: Poly- $\beta$-hydroxybuttersaure abbauende bakterien und exo-enzyme. Archives of Microbiology, 47, 167-200 (1963).

[77] Lee S. Y.: Bacterial polyhydroxyalkanoates. Biotechnology and Bioengineering, 49, 1-14 (1996).

DOI: $10.1002 /($ SICI $1097-0290(19960105) 49: 1<1::$

$$
\text { AID-BIT1>3.0.CO;2-P }
$$

[78] Reddy C. S. K., Ghai R., Rashmi, Kalia V. C.: Polyhydroxyalkanoates: An overview. Bioresource Technology, 87, 137-146 (2003).

DOI: $\underline{10.1016 / \mathrm{S} 0960-8524(02) 00212-2}$ 
[79] Tokiwa Y., Iwamoto A., Koyama M., Kataoka N., Nishida H.: Biological recycling of plastics containing ester bonds. Makromolekulare Chemie, Macromolecular Symposia, 57, 273-279 (1992).

DOI: $10.1002 /$ masy. 19920570125

[80] Calabia B. P. T., Tokiwa Y.: Microbial degradation of poly(d-3-hydroxybutyrate) by a new thermophilic Streptomyces isolate. Biotechnology Letters, 26, 15-19 (2004).

DOI: 10.1023/B:BILE.0000009453.81444.51

[81] Sanchez J., Tsuchii A., Tokiwa Y.: Degradation of polycaprolactone at $50^{\circ} \mathrm{C}$ by a thermotolerant Aspergillus sp. Biotechnology Letters, 22, 849-853 (2000). DOI: $10.1023 / \mathrm{a}: 1005603112688$

[82] Tseng M., Hoang K-C., Yang M-K., Yang S-F., Chu W.: Polyester-degrading thermophilic actinomycetes isolated from different environment in Taiwan. Biodegradation, 18, 579-583 (2007).

DOI: $10.1007 / \mathrm{s} 10532-006-9089-\mathrm{Z}$

[83] Koyama N., Doi Y.: Miscibility of binary blends of poly $[(R)-3$-hydroxybutyric acid] and poly[ $(S)$-lactic acid]. Polymer, 38, 1589-1593 (1997).

DOI: $10.1016 / \mathrm{S} 0032-3861(96) 00685-4$

[84] Johnstone B.: A throw away answer. Far Eastern Economic Review, 147, 62-63 (1990).

[85] Brandl H., Gross R., Lenz R., Fuller R.: Plastics from bacteria and for bacteria: Poly( $\beta$-hydroxyalkanoates) as natural, biocompatible, and biodegradable polyesters. Advances in Biochemical and Engineering Biotechnology, 41, 77-93 (1990).

[86] Rizk S., Connelly D. W., Bernasconi M., Carter A. J., Martin D. P., Williams S. F.: Injection molding of poly-4-hydroxybutyrate. U.S. Patent 20130309166, USA (2013).
[87] Misra S. K., Ohashi F., Valappil S. P., Knowles J. C., Roy I., Silva S. R. P., Salih V., Boccaccini A. R.: Characterization of carbon nanotube (MWCNT) containing $\mathrm{P}(3 \mathrm{HB}) /$ bioactive glass composites for tissue engineering applications. Acta Biomaterialia, 6, 735-742 (2010).

DOI: $10.1016 /$ j.actbio.2009.09.023

[88] Bucci D. Z., Tavares L. B. B., Sell I.: PHB packaging for the storage of food products. Polymer Testing, 24, 564-571 (2005).

DOI: $10.1016 /$ j.polymertesting.2005.02.008

[89] Miguel O., Fernandez-Berridi M. J., Iruin J. J.: Survey on transport properties of liquids, vapors, and gases in biodegradable poly(3-hydroxybutyrate) (PHB). Journal of Applied Polymer Science, 64, 1849-1859 (1997).

DOI: 10.1002/(sici)1097-4628(19970531)64:9<1849:: aid-app22>3.0.co;2-r

[90] Chen G-Q.: Biofunctionalization of polymers and their applications. Biofunctionalization of Polymers and their Applications, 125, 29-45 (2011).

DOI: $10.1007 / 102010 \quad 89$

[91] Kosior E., Messias R., Fowler P.: Lightweight compostable packaging: Literature review. The Waste and Resources Action Programme, Banbury (2006).

[92] Bhatt R., Patel K., Trivedi U.: Biodegradation of poly (3-hydroxyalkanoates). in 'A handbook of applied biopolymer technology: Synthesis, degradation and applications' (eds.: Sharma S. K., Mudhoo A.) The Royal Society of Chemistry Publishing, London, 311-331 (2011).

DOI: $10.1039 / 9781849733458-00311$ 